\title{
De la desnaturalización de la religión y de la política a la absolutización del yo
}

Carlos Daniel Lasa*

Universidad Nacional de Villa María;

Universidad Nacional de Córdoba;

CONICET

cdlasaga@gmail.com
Revista Cultura Económica

Año XXXIX $\bullet \mathrm{N}^{\circ} 102$

Diciembre 2021: 45-67

https://doi.org/10.46553/cecon.39.102.2021.p45-67

Resumen: El presente escrito analiza, desde la propuesta filosófica de Augusto Del Noce, la transformación de la religión en política y de la política en religión. Esta última la política transformada en religión- se encarna en el marxismo que promete la salvación del hombre a través de la acción transformadora del mundo. Sin embargo, al no poder conciliar revolución con libertad, el marxismo se suicida. La esfera política, así, solo siembra el escepticismo, y al hombre le queda un único refugio: su yo.

Palabras clave: Del Noce; Religión; Política; Marxismo

From the distortion of religion and politics to the absolutization of the self

Abstract: From the philosophical perspective of Augusto Del Noce, this article explores the transformation of religion into politics and politics into religion. The latter -politics transformed into religion- has being embodied by Marxism, that promises the salvation of the human being through the transforming action of the world. Unable to reconcile revolution with freedom, yet, Marxism commits its own suicide. Thus the political sphere only brings scepticism, and humans have only one shelter left: their own self.

Keywords: Del Noce; Religion; Politics; Marxism

* Recibido: 24/07/2021 - Aprobado: 25/11/2021 


\section{Una breve introducción}

El presente artículo se desarrollará en tres momentos. En el primero mostraremos cómo la historia contemporánea es el resultado de una filosofía "que se ha hecho mundo", esto es, la filosofía marxista. En efecto, es esta filosofía la que, a partir de las categorías de "revolución" y de "nihilismo", permite enhebrar y comprender los acontecimientos de la historia contemporánea. Esta última es, precisamente, el resultado del cumplimiento del marxismo y de su suicidio, que conduce el nihilismo. El marxismo ha sido el responsable, como lo mostraremos, de haber desnaturalizado la política al pretender convertirla en acción redentora de la naturaleza humana.

En el segundo momento, nos ocuparemos de seguir el itinerario de la religión cristiana, en particular del catolicismo, en su proceso de modernización, es decir, de inmanentización. Aquí haremos hincapié en la aceptación acrítica, por parte del catolicismo, de una idea de modernidad acuñada por los pensadores iluministas. Esta actitud acrítica lo ha conducido, en una primera instancia, a la condena en bloque de toda la modernidad. Luego, para no quedar fuera de la historia, ha comprado esa idea de modernidad que los iluministas configuraron y, como consecuencia de ello, ha forjado un nuevo cristianismo huérfano de toda instancia sobrenatural. El resultado ha sido la inmanentización absoluta de la religión y su identificación con la política.

En el tercero, referiremos nuestra situación contemporánea. El hombre ha dejado de confiar en la dimensión política porque ella le ha generado un profundo escepticismo. Es decir, le ha prometido algo que jamás ha podido cumplir: otorgarle la plena felicidad y libertad. Pero este mismo hombre también ha dejado de confiar en una religión, que ha renunciado a ocuparse de su objeto propio y se ha mundanizado. La religión ha devenido política. Por esta razón, el hombre ha optado por refugiarse dentro de su propio yo. Es un yo que, marginado de toda verdad, bien y belleza, busca solo satisfacer su vida biológica. De allí que, haciendo referencia a la obra de Max Stirner El Único y su propiedad, decimos que vivimos bajo el reinado del Único. 


\section{La política convertida en religión}

Augusto Del Noce, siguiendo a Jean Laporte, considera que el racionalismo debe ser definido en relación a la religión. Laporte refiere que el racionalismo

[...] rechaza toda trascendencia. Se cierra en la inmanencia porque piensa que la razón, nuestra razón, no se funda sobre ninguna otra cosa, no tiene necesidad de completarse por una cosa distinta de ella, y, por lo tanto, no debe ocuparse de ningún más allá. [...] Ya jamás tolerará lo sobrenatural (Laporte, 1950: XIX).

Junto con el rechazo de la esfera sobrenatural, el racionalismo también rebate la existencia del pecado original tal como la concibe la Sagrada Escritura. Esta negación conducirá, entre otras cosas, a las concepciones políticas que Antonio Rosmini (1997: 104) denominará "perfectistas", cuyo denominador común será el totalitarismo. De ahora en más, el mal, al no afectar a la naturaleza humana, ya que se encuentra fuera de su ejido, podrá ser finalmente eliminado de la historia. Es decir, el mal es propiedad de un sistema opresor que estaba negando la libertad humana.

La acción humana pasará a tener una función soteriológica ya que mediante ella será posible crear un estado intrahistórico de felicidad plena para el hombre. Y esa acción, como ya podrá advertirse, será eminentemente política. De este modo, esta acción política redentora declara la inutilidad de la existencia del Soter divino, Jesucristo.

\section{¿Cómo se ha producido este corrimiento?}

Para Del Noce, la filosofía de Marx ha sido determinante en la configuración del mundo contemporáneo. La historia contemporánea, nos dice, es la misma filosofía marxista que se ha hecho mundo. El verdadero motor de la historia, para el pensador italiano, no está en la causa material constituida por conflictos de clase o por el progreso tecnológico. La verdadera causa de la historia contemporánea está constituida por la causa formal, esto es, por la configuración de la misma a partir de la filosofía marxista.

Es el marxismo, en cuanto causa formal, el que configura a la causa material a partir de dos categorías: la idea de revolución y la de nihilismo (Del Noce, 2007a: 62-63). De allí que, para el pensador italiano, la historia 
contemporánea no sea otra cosa que el auge del marxismo a partir de su concepción revolucionaria, pero, además, su suicidio y su pasaje al nihilismo (Del Noce, 2007a: 61).

Del Noce concibe la idea de revolución en Marx como la resultante de la idea de cambio y de la dialéctica. Mediante esta última se produce el deceso de toda finitud y, por eso, de todo valor que sea pensado como absoluto y eterno. Toda realidad finita es un momento irrelevante dentro del devenir de la totalidad. Del Noce está pensando en aquella cita de Engels referida a la dialéctica cuando afirma que

\begin{abstract}
[...] esta filosofía dialéctica acaba con todas las ideas de una verdad absoluta y definitiva y de un estado absoluto de la humanidad, congruente con aquella. Ante esta filosofía, no existe nada definitivo, absoluto, consagrado; en todo pone de relieve lo que tiene de perecedero, y no deja en pie más que el proceso ininterrumpido del devenir y del perecer [...] su carácter revolucionario es absoluto, es lo único absoluto que deja en pie (Engels, 1955: 382).
\end{abstract}

Si todo es devenir, como refiere Engels, y el hombre ya no mantiene una relación constitutiva con el Creador (religio), en consecuencia, ya no tiene que responder ante Él. La única dimensión estrictamente humana será la histórico-política (Tesis VI de Marx sobre Feuerbach). Desde esta perspectiva puede entenderse la absorción de la ética por parte de la política revolucionaria.

Consecuentemente, nos dice Del Noce, "La realidad que seguirá a la revolución se presentará como una realidad completamente diversa de la realidad precedente, una realidad completamente nueva señalada solo a través de negaciones" (Del Noce, 2007a: 63). La revolución, de este modo, cumplirá una sustitución. La racionalidad intrínseca a la realidad es reemplazada por la instauración de una meta-humanidad que recupera sus poderes. ¿Cuáles? Aquellos que el hombre había perdido al proyectarlos en Dios (Del Noce, 1980: 148).

Para nuestro filósofo, lo fundamental del marxismo radica en su filosofía. Marx no es un mero repetidor de Hegel. Su grandeza especulativa consiste en haber ofrecido una nueva concepción de la filosofía que va a posibilitar la reconciliación perfecta del pensamiento con la realidad. 
Para Marx, la filosofía hegeliana está fundada en una lógica de la comprensión que teologiza lo real. Si bien Hegel pretendía evitar toda teologización de lo finito, termina por elevar a esta categoría a una realidad empírica que es el Estado prusiano. En él culminan las parábolas de la filosofía y la historia.

Por esta razón, Marx refunda epistemológicamente la filosofía al sustituir la lógica de la comprensión por la de la revolución.

La filosofía, a partir de Marx, no es más teoría sino, esencialmente, acción transformadora. Refiere Del Noce: "La filosofía del primado de la acción dirigida a transformar la acción termina identificándose con la acción dirigida a transformar el mundo político-social, es decir, con la revolución” (Del Noce, 1980: 145).

Del Noce señala que en la tesis VI de Marx sobre Feuerbach se encuentra la clave para entender todo el pensamiento marxista (Del Noce, 1980: 137). Aquí, Marx define a la esencia humana como el conjunto de relaciones sociales. Refiere el pensador italiano:

Con rigor estricto, se debería llegar a la conclusión de que no se puede siquiera hablar de la realidad del hombre, en cuanto que no existe un hombre que entra en relaciones sociales, sino que existe, en cambio, la sociedad como realidad global, de la cual los individuos son los elementos [...] (Del Noce, 1980: 137).

En esta tesis, afirma Del Noce, se encuentra el fundamento del materialismo histórico. De ahora en más, para configurar a un hombre sin Dios bastará con modificar o cambiar las relaciones sociales.

La tesis VI sobre Feuerbach implica privar al espíritu humano de la participación de un Logos eterno. Al negar la idea de participación, de cuño platónico, se oblitera la interioridad metafísica, es decir, la presencia de la verdad eterna en la mente humana. Luego, solo queda un sujeto entendido en términos de actividad práctico-sensible. Este sujeto va a ser portador de deseos que es menester satisfacer mediante la modificación de la naturaleza a través del trabajo (Del Noce, 1972: 42).

Esta absorción del sujeto por parte del trabajo es la consecuencia de la negación de la intuición intelectual del ser en tanto verdad interior. El abandono de la interioridad metafísica supone la ausencia de un núcleo 
autónomo en la sociedad política. En su lugar, queda un hombre unidimensional, reducido a mera actividad transeúnte y esculpido a partir de los intereses que gobiernan en la polis.

Ahora bien, este marxismo, como lo señalamos precedentemente, lleva en su misma entraña una contradicción insalvable. Era aquello que Del Noce denominaba heterogénesis de los fines. El marxismo, en efecto, tenía en vista dos fines simultáneos que, de suyo, colisionaban. La realización de uno equivalía a la desaparición del otro.

Estos fines eran: alcanzar el reino de la libertad dentro de la historia, por un lado; por el otro, disponer de la necesaria revolución para conquistarlo. Sin embargo, el paso a través de la revolución no va a ser un mero trámite. Por el contrario, supone un asentamiento, un detenimiento en ese medio que termina convirtiéndose en fin. Y por eso, se va a absolutizar el momento de la fuerza en detrimento total del estado utópico que suponía la plena realización de la libertad en este mundo.

\section{Expresa muy agudamente Del Noce:}

[...] el marxismo es, en todas sus facetas, la mayor conciliación de opuestos que haya sucedido en la historia del pensamiento. El utopismo llevado a su máxima expresión, se concilia con el extremo realismo político; la forma más radical del ateísmo con aquella que podría ser llamada la última gran religión [...] la unidad de materialismo y dialéctica, conducidos, también ellos, al máximo nivel [...] Pero, ¿qué ha sucedido en el proceso de su realización? El momento utopista ha desaparecido, y ha permanecido aquel realismo político que se ha expresado en aquella novedad que es el totalitarismo [...] (Del Noce, 1983: 21).

La política soteriológica ha confirmado, históricamente, su más absoluto fracaso. Sus pretensiones de dar plena satisfacción a las exigencias del hombre han naufragado. ¿Qué ha quedado? Del Noce nos dice que el resultado de toda esta hybris de la política ha desembocado en la sociedad de la opulencia.

Pero dejemos esta cuestión para referirla en la última parte de nuestro escrito. Ocupémonos, ahora, del proceso mediante el cual la religión, y en particular la religión católica, ha sido convertida en política. 


\section{La religión convertida en política}

Uno de los grandes problemas de Tomás de Aquino y de los teólogos cristianos fue el de determinar qué filosofía era la más apta para comprender la fe. La aptitud de la filosofía a emplear se medía por su capacidad de comprender, de la mejor manera y sin llegar a corromperlo, lo creído.

Esta cuestión, muy presente en la teología católica, se fue desdibujando durante el siglo XX. La convicción que se tenía respecto del contenido de la fe católica cambió de objeto. Para algunos católicos, el principal contenido del nuevo dogma pasó a ser una determinada interpretación de la historia moderna. Y a partir de este nuevo dogma, se ocuparon de elegir aquella filosofía que fuera más acorde con esa interpretación. Y esa filosofía no fue otra más que el racionalismo que modificó sustancialmente la fe católica.

¿Cómo se produjo, exactamente, este pasaje?

Durante el siglo XIX se produce, en Piacenza, el movimiento filosófico neo-tomista. Su padre mentor fue Vincenzo Benedetto Buzzetti y sus sucesores, los hermanos Sordi, Giovanni M. Cornoldi, Guido Mattiussi, entre otros (Dezza, 1940: 14)².

El movimiento neo-tomista asumió una idea de modernidad que condicionó de modo radical a la cultura católica, por lo menos hasta mediados del siglo XX (Malusa, 1982: 103). La actitud de todos los exponentes de la primera generación del neotomismo italiano fue la de condenar absolutamente a la modernidad. La modernidad era juzgada, por el Padre Cornoldi, en estos términos:

La historia de las modernas filosofías no es otra cosa que la historia de las aberraciones intelectuales del hombre abandonado a los vértigos de su orgullo; tanto que, como otros bien dicen, se podría llamar a esa historia: la patología de la humana razón (Cornoldi, 1872: XXIII).

Ahora bien, es preciso advertir que este rechazo se realiza sobre una idea de modernidad acuñada por autores iluministas. Estos últimos (Pierre Bayle, Lessing, Condorcet, etc.) han sostenido un concepto axiológico, no cronológico, de modernidad. 
Modernidad, para estos autores, es el camino que la razón humana emprende hacia la radical inmanencia. Modernidad equivale, por lo tanto, a la afirmación de la subjetividad y a la autonomía absoluta del hombre. En definitiva, se trata de una actitud de ruptura total con la tradición.

De este modo, nos dice Del Noce, "Moderna es hoy toda filosofía que se presenta no como aquella que pone en acto una 'virtualidad' del pensamiento antiguo o de la unidad medieval del pensamiento antiguo y moderno", sino como "un período de la búsqueda filosófica caracterizado por una cesura respecto del griego y del medieval los cuales son considerados como terminados" (Del Noce, 1982: 27). Este corte, es interesante ponerlo de manifiesto, ya comienza con Descartes, el así considerado padre de la modernidad.

Los pensadores católicos, en lugar de problematizar la referida idea de modernidad, la asumen in totum y luego la niegan en bloque. A esta posición de condena, por parte de los católicos, Del Noce la denomina integrismo.

Su defecto lógico, para Del Noce, consiste "en una subalternación a Bayle, en la oposición como inversión" (Del Noce, 1994: 31). Ahora bien, esta posición ha engendrado tanto al modernismo como al progresismo posterior. Señala Del Noce que es un hecho bastante conocido
[...] la conexión necesaria del integrismo con su sombra, el modernismo y el progresismo. El pasaje al progresismo se ha verificado, en efecto, en todas las formas de pensamiento que han acogido la visión integrista de la historia: en el tradicionalismo de Lamennais, en una cierta forma en el ontologismo de Gioberti (aunque aquí el problema es extremadamente complejo), en el renacimiento tomista con el modernismo de los primeros decenios de nuestro siglo y con el progresismo de 1953 hasta hoy (Del Noce, 1994: 31).

¿Por qué se da este pasaje, que Del Noce caracteriza como necesario, del integrismo al modernismo y luego al progresismo?

El filósofo italiano no hace referencia a las razones que son la causa del referido pasaje. Nosotros entendemos que el fenómeno puede ser explicado a partir de la naturaleza misionera de la Iglesia. 
En efecto, la exigencia de los católicos de evangelizar les impedía asumir la posición de condenar en bloque al mundo moderno. Por el contrario, tomaron una actitud de reconquista, de recuperación de ese mundo que se les aparecía como totalmente perdido. Para ello, pensaron que debían emprender un camino de signo totalmente contrario al de la posición integrista: hacerse modernos. La Iglesia entera debía parecer moderna.

Esta posición ya se registra a mediados del siglo XIX en el filósofo italiano Vincenzo Gioberti, "el líder desconocido del modernismo católico"3. En su escrito Della riforma cattolica della Chiesa, Gioberti expresa la necesidad de cambio radical en la Iglesia católica: un cambio que la pusiera a tono con la modernidad.

\section{Refería Gioberti:}

Contradicción entre el siglo y el modo en el cual es entendido el cristianismo. Aquel es progresivo; sin embargo, este otro es todavía expuesto en aquella forma que tenía en edades regresivas. De aquí nace su decadencia. De allí la necesidad de una reforma que ponga al cristianismo de acuerdo con el siglo. Por eso, sin despojarlo de su finalidad celeste, es necesario desarrollar el elemento terreno del mismo y hacer una civilización. Tal reforma debe abrazar la explicación del dogma, la dirección del culto y el genio de la jerarquía. Roma es todavía hoy aquello que era en el medioevo. De allí su declinación4 (Gioberti, 1856: XXIII, 37).

\section{Y añade Gioberti:}

Las restauraciones son ascendentes o descendentes. Las primeras retornan a lo antiguo avanzando hacia lo nuevo; y duran. Las segundas retornan a lo viejo y se oponen a lo nuevo; no prosperan. Las unas son conformes a la ley del progreso cósmico; las otras son contrarias. Las primeras son dialécticas, las segundas sofísticas. Las unas metésicas 5 y las otras miméticas [...] El catolicismo se puede restaurar de dos modos. La restauración del segundo género que hoy se hace es vana, además de perniciosa; logra el efecto contrario [...] la restauración del segundo género es retrógrada, no es orgánica, no es creativa. Toda restauración que quiera durar debe ser una evolución, una transformación, y por lo tanto una creación. Digo transformación, no deformación (Gioberti, 1856: LXXXV, 136) ${ }^{6}$. 
Del Noce observa cómo en la concepción de Gioberti, la religión católica se alinea a las ideas de desenvolvimiento y de progreso, acordes a la visión filosófica racionalista (Del Noce, 1990a: 202).

Gioberti intenta llevar a cabo una reforma de la Iglesia católica que ponga al cristianismo de acuerdo con el siglo. Para ello, como ya quedó expresado en su cita, será preciso desarrollar su elemento terreno y convertirlo en promotor de la civilización. Esto solo será posible a partir de una profunda reforma de la teología católica. La misma va a involucrar el abandono de una filosofía del ser de matriz helénica.

Gioberti utiliza la figura del polígono para representar esta reforma. El polígono es una imagen geométrica que tiene muchos lados. Él parangona el polígono con lo verdadero y con lo flexible (Gioberti, 1856: XX, 29). Lo verdadero está dotado de una potencia interminable. Por esta razón, el dogma católico solo podrá ser recibido por un hombre subjetivado. Esta subjetivación, precisa el mismo Gioberti, equivale a una segunda creación de lo verdadero objetivo (Gioberti, 1856: XXIV, 39).

Conviene comentar que, para este autor, el dogma se encuentra en potencia. Y esta potencia es inmutable, no así su actualización; es decir, la comprensión del mismo, tanto a nivel teórico como a nivel de la práctica disciplinaria. El acto varía continuamente porque se ejecuta en el tiempo (Gioberti, 1856: XXI, 32). De allí que el dogma sea siempre progresivo y se adapte a todos los individuos (Gioberti, 1856: XXIV, 39).

La esencia de la definición dogmática, nos dirá Gioberti, es negativa. La definición dogmática indica aquello que no se debe creer, dejando librado al creyente aquello concreto que él debe creer. Por eso, continúa Gioberti,

[...] la última concretización del dogma, dependiente del individuo, puede y debe variar. Así el dogma pasa de objetivo a subjetivo, se transforma en dúctil, progresivo, acomodable al temperamento de los individuos, de lugares y de los tiempos [...], expresa [...] siempre un lado verdadero de la cosa de la poligonía objetiva de lo verdadero (Gioberti, 1856: XLVII, 77).

Por otra parte, Del Noce también indica al filósofo católico Jules Lequier como un precursor del modernismo católico. Y lo identifica como tal por cuanto este separa, como lo hace todo modernista, la revelación del 
pensamiento griego. Para Lequier, la filosofía griega estaría impidiendo, a partir del principio de creación y de la idea personalista, comprender la fe (Del Noce, 1992: 160).

La razón modernista de esta separación entre filosofía griega y revelación judeo-cristiana está dada por la necesidad de la teología católica de adaptarse al mundo moderno. La filosofía griega, como quedó expresado, sería la causa que obstaculiza esa operación. Lequier hubiese coincidido plenamente con la calificación que Giovanni Gentile, décadas después, expresó acerca del pensamiento griego, más precisamente, del pensamiento platónico: “[...] idealismo estático, intelectualista, gobernado por el ideal de una verdad absoluta, eterna, objetiva, frente a la cual el hombre se muestra como un espectador" (Gentile, 1962: 35-36).

Del Noce reconoce como una de las notas típicas y más características del pensamiento modernista la separación entre filosofía griega y revelación divina. Sin embargo, el movimiento modernista, a juicio de Gentile, se queda a mitad de camino. Giovanni Gentile le reprocha a uno de los modernistas, concretamente a Laberthonière, la incongruencia del modernismo que "[...] quiere ser un método de inmanencia [...] y presupone un objeto trascendente" (Gentile, 1962: 24).

Si la verdad, según el método de la inmanencia, la construye el hombre, entonces no puede afirmarse la existencia de un Dios. No hay lugar para un Dios totalmente acabado, perfecto, situado más allá de la única verdad que es de factura humana.

Esta inconsistencia teórica advertida por Gentile desaparecerá por completo en el neo-modernismo, progresismo católico o "modernismo que ha asumido su plenitud" (Del Noce, 1994: 151). El progresismo católico es correlativo, nos dice nuestro filósofo, a aquella gran crisis de valores que se inició en Europa después de 1930 y que preparó la Segunda Guerra Mundial (Del Noce, 1994: 148).

El principio del progresismo católico, según Del Noce, descansa en un juicio histórico-político (Del Noce, 2015: 39). Esta postura consiste en asumir, de modo totalmente acrítico, la visión iluminista de la historia. Este punto de partida se convierte, para todo el pensamiento progresista, en el dogma principal. 
Veamos: el progresismo católico adhiere a la tesis de que el secularismo (es decir, la absoluta autonomía del mundo y del hombre) es la fruta madura del mismo cristianismo. La causa hay que buscarla en aquella idea de razón crítica7, cuya noción sucedánea es la idea de revolución que permite que el hombre alcance la edad adulta.

Sin embargo, esta revolución no había sucedido históricamente. Faltaba la aparición del marxismo para hacerla realidad. La liberación plena de la humanidad debía concretarse dentro de la historia misma.

De allí el apego al marxismo por parte de la teología progresista. Claro está que no es la adhesión al materialismo dialéctico. El consentimiento va a darse con el marxismo en tanto ciencia de la sociedad, en tanto instrumento para liberar al hombre de las alienaciones que lo aprisionan.

El cristianismo, habiendo abandonado la dimensión sobrenatural y metafísica, se encontrará ahora en condiciones de alcanzar su plena madurez. Así, podrá garantizar las mejores condiciones para el desarrollo pleno de la humanidad.

Se trata, en verdad, de un nuevo cristianismo: uno que termina siendo absorbido por la dimensión política en tanto fuerza constructiva del progreso social.

Resulta pertinente comentar que, por nuestros días, concretamente en Argentina, se cultiva una teología denominada "teología del pueblo". Esta ha conducido a la pérdida de la centralidad del Dios revelado en el acto religioso. Nos hemos referido a la misma, in extenso, en un artículo que publicáramos en el año 2017 (Lasa, 2017).

El grave problema de esta pseudo-teología, reside en su mismo punto de partida: declara la imposibilidad de la inteligencia humana de leer el orden eterno del ser. Contrariamente a Agustín, cuyo gran problema era cómo acceder a lo sobrenatural, cosa que, como expresa Gilson, se convirtió en una de las raíces más profundas de su doctrina de la iluminación ${ }^{8}$.

La "teología del pueblo", contrariamente a la posición agustiniana, sostiene que la razón humana no puede conocer ninguna realidad que se encuentre situada más allá del ámbito de lo histórico. La visión metafísica, universalista, para los pensadores de esta nueva teología, desvaloriza el campo de lo fáctico, del haber, del estar. 
En el principio no encontramos ningún orden del ser, ninguna representación conceptual, sino la vida en acto. Existe un "hay" inicial que, en lugar de exigir el ver (contemplar), pide el hacer. Y a ese hacer inicial, que se mueve en todas direcciones, ninguna lógica puede fijarle un centro so pena de perderlo. Todo decir, toda reflexión no puede ser ejercida sino sobre ese hay primero que es, fundamentalmente, histórico. En este sentido, Dios, como objeto de la especulación humana, queda totalmente fuera de su alcance. De allí que sea considerado como "lo completamente otro".

Hay que renunciar, entonces, a hablar acerca de Dios. Todo discurso que la inteligencia humana intente formular sobre Dios será para convertirlo en un ídolo que nada tiene que ver con el verdadero Dios.

Ahora bien, si Dios queda reducido al ámbito de lo absolutamente desconocido, entonces es lógico concluir que el acto específicamente religioso no encuentra en Dios su aspecto central. Y si la realidad de Dios queda fuera del alcance del espíritu humano, ¿qué sentido tendría mantener la distinción entre lo sagrado y lo profano?

En realidad, la sacralidad es una dimensión carente de todo sentido; en consecuencia, el ámbito de lo religioso sufrirá, de modo irremediable, una lamentable desacralización.

Pero hay más. También la doctrina católica y sus fórmulas dogmáticas dejarán de ocupar un lugar central en la fe. En efecto, si Dios no puede ser conocido, en consecuencia, todas las fórmulas que hagan referencia a Él no serán otra cosa más que descripciones idolátricas.

De este modo, la esencia del cristianismo pasa a identificarse con el amor entre los hombres. El obstáculo doctrinal de la Iglesia católica que, en lugar de unir a todos los hombres como hermanos los separaba, finalmente ha sido superado por la nueva Iglesia. El criterio de verdad, ahora, es el sostenido por Marx en su tesis II sobre Feuerbach: la verdad del cristianismo se comprobará en la existencia de una fraternidad entre los hombres.

La conversión inmanentista que la religión católica sufre por nuestros días es una confirmación más de la aguda y correcta hermenéutica delnociana. 


\section{El camino hacia el Único}

Del Noce ha señalado, como ya lo referimos anteriormente, que del suicidio del marxismo ha sobrevenido la actual sociedad de la opulencia. Esta sociedad permisiva se caracteriza, entre otras cosas, por la presencia de la "irreligión natural". Para esta, nos dice el filósofo italiano, el tema de Dios ha pasado a ser una cuestión inútil. El hombre de nuestros días no tiene necesidad alguna de Dios.

Esta irreligión natural se asienta sobre una filosofía empirista. El empirismo es una fase posterior de aquel racionalismo que se configura a partir de una apuesta negativa respecto de lo sobrenatural y de la naturaleza humana caída. El empirismo prescinde completamente de esa opción, fundándose exclusivamente sobre la distinción entre aquello que es verificable y lo que no lo es (Del Noce, 1990b: 298).

Del Noce concibe al empirismo como una forma de pensamiento que pretende “[...] reafirmarse más allá del racionalismo, pero luego de haber aceptado las negaciones del mismo [...]. En realidad, [...] el término más conveniente para designarlo es el de positivismo (ciencia contra la teología y la metafísica)" (Del Noce, 1990b: 19).

Si el nuevo empirismo pone a la ciencia contra la religión y la metafísica, se entiende, entonces, que el hombre tenga una fe incondicionada en el progreso de la técnica. De allí que asuma una visión del conocimiento unidimensional: el conocimiento válido, exclusivo $\mathrm{y}$ excluyente, es el tecno-científico. Desde esta perspectiva puede comprenderse, por ejemplo, la desaparición de la universidad a causa del dominio absoluto, en el mundo cultural, del espíritu fenicio en detrimento del espíritu heleno.

Nos interesa señalar, fundados en los derroteros tanto de la política como de la religión seguidos por Del Noce, que el hombre actual ha sido conducido a encerrarse dentro de su propio ser. Y la causa de esta realidad se encuentra en la desnaturalización que han sufrido esas dos dimensiones tan importantes para el ser humano: la religión y la política.

¿Tendría sentido que el hombre contemporáneo recurriese a la religión en busca del sentido de su existencia y de su salvación? Ciertamente que no. 
También la religión ha absolutizado la historia, no dejando cabida para algo que sea verdadero y eterno. En su lugar, ha asumido una filosofía hermenéutica que vive en, para y de la historia. Por esta razón, la religión ha dejado de prometer al hombre la curación de su infirmitas, de su falta de firmeza, de la inconsistencia en su ser.

La religión cristiana prometía al hombre una solución que, debido a la ineludible realidad de la muerte, no podía encontrar dentro del devenir histórico. La solución solo podía venir de la Firmeza misma. Aquel ser que subsiste en sí y por sí mismo, y que es la Eterna presencia, va a participarlo de su permanencia.

Ese Dios eterno, enseñaba la Iglesia católica, no quiso permanecer encerrado dentro de sí, sino que va a participar de su ser a todo lo creado. Incluso, ingresa en la fugacidad y mortalidad de la vida humana para hacerla eterna. Dios quiere recrear al hombre haciéndolo formar parte de su inmortalidad. Y lo hace de dos modos: le otorga la permanencia en su ser, y lo hace partícipe de su propia vida a través de la Gracia.

¿Qué sucede cuando el progresismo católico absolutiza la dimensión histórica, declarando imposible la existencia de un Dios?

La proclamada secularización abandona aquella promesa de salvación de una vida definitiva y feliz para el hombre. La propuesta pseudoreligiosa del nuevo cristianismo consiste en satisfacer aquellos deseos de todo hombre dentro de una dimensión puramente histórica.

El mal, para esta nueva Iglesia, al igual que para Rousseau, no está ligado al pecado original, sino a la existencia de una organización políticosocial que se contrapone a una naturaleza buena. De allí la necesidad de restaurar la naturaleza mediante la acción humana: una tarea eminentemente política.

En este sentido, el mejor servicio que puede cumplir la religión es el de anunciar la existencia de un Dios común a todos los hombres que los vincule, de manera amical, entre sí y en relación a la madre naturaleza. Ya no se trata de restaurar todas las cosas en Cristo.

¿Quién hubiese imaginado que el catolicismo llegase a predicar la hermandad universal, como si la filiación con Dios correspondiese al orden de la naturaleza y no al de la Gracia? 
El nuevo Dios es pensado, al modo de un garante, en función de la pax universal. Esta última podrá concretarse siguiendo las exigencias de la pura naturaleza la cual no está herida por el pecado original. El hombre está en condiciones de crear un mundo dentro del cual construya la plena felicidad. Ni Rousseau hubiese imaginado que el catolicismo fuera a adquirir, con el paso del tiempo, esta nueva forma.

Rousseau consideraba que el católico era un enemigo de la ciudad ideal en virtud de su intolerancia dogmática (Del Noce, 2016: 48). Sucede que, en tiempos de Rousseau, la cuestión de la verdad, para todo el catolicismo, era una instancia fundamental.

Para esta nueva concepción religiosa, por el contrario, la cuestión de la verdad ha dejado de ser un problema. Habiendo asumido la filosofía de la praxis o del devenir, ha diluido la condición de posibilidad de la existencia de una verdad eterna, situada más allá del devenir temporal.

La conciencia histórica ha reemplazado a la matriz metafísica. Y cuando decimos "conciencia histórica" lo decimos en los términos de Gadamer: "tanto el conocedor como lo conocido, tanto el sujeto como el objeto no se dan 'ónticamente', sino 'históricamente”' (Gadamer, 1993: 25).

La historia, como refiere Jacques Maritain,

[...] se ha transformado para ellos en el Salvador y el Redentor. La primordial obligación moral, entonces, es seguir el ritmo de la historia y tener eficacia histórica y éxito en la historia. El que no tiene éxito es condenado, justamente condenado, pues ha pecado contra la historia (1971: 63). Olvidaron, nada más ni nada menos, que los cristianos "No somos cooperadores de la historia; somos cooperadores de Dios” (1971, 62).

De allí, entonces, que la filosofía haya dejado de ser búsqueda de la verdad para convertirse en ideología, esto es, un discurso que vehiculiza meros intereses. Referimos al respecto lo que señaláramos en un escrito sobre la denominada "teología del pueblo":

La filosofía no tiene ya como finalidad la búsqueda de la verdad sino la de cooperar con el proyecto del pueblo, para que este pueda desarrollarse de acuerdo a su peculiar modo. La filosofía deja de ser amor al saber para convertirse en ideología: instrumento exclusivo al servicio del poder de un determinado modo de estar. 
La filosofía ya no tendrá como finalidad dar cuenta de la estructura inteligible de lo real: solo deberá servir a la autoafirmación del pueblo (Lasa, 2017: 242-243).

Evidentemente, la renuncia a la metafísica ha significado una gran pérdida para el catolicismo. Y el menoscabo está dado por la redefinición de un cristianismo en términos no metafísicos, lo cual equivale a reducir al cristianismo a un "[...] proyecto de libertad y de justicia en el mundo histórico, social, humano, finito" (Del Noce, 2007: 318). En definitiva, a un proyecto humano, demasiado y únicamente humano.

Ahora bien, el hombre actual no puede abrigar muchas esperanzas en lo que se refiere a la dimensión política. Esta última, habiéndose desnaturalizado, promete al hombre la salvación. Sin embargo, la realidad del mal transforma la oferta en una profunda desilusión.

En lugar de volver a pensarse desde una visión metafísica, la política siguió enfocándose a partir de la misma filosofía racionalista. Una filosofía que, ciertamente, la condujo a su megalomanía, aunque, en esta nueva versión, hubo de renunciar, con algo más que vergüenza, al ideal mesiánico preconizado por Marx.

Al respecto, el discípulo de Del Noce, el filósofo italiano Danilo Castellano (2011: 369-370), señala tres características de la actual concepción de la política: su carácter absolutamente convencional y operativo, su perfil cuantificador, y su modo consensual.

La política, en cuanto ciencia, se ha reducido a método. ¿Qué significa esto? Se trata de un proceso coherente y rigurosamente deducido de postulados que no se demuestran. O también, se deriva de hipótesis que se asumen como si fuesen verdaderas (carácter operativo). La ciencia política, además, se transforma en cuantificadora ya que, al poseer un carácter puramente convencional, solo enseña el modo de conquistar o conservar el poder. Para alcanzar este objetivo se vale de cálculos matemáticos, de sondeos, de estadísticas.

La política, nos dirá Castellano, deja de ser filosófica para convertirse en sociológica. La ciencia política se hace politología (carácter cuantificador). Finalmente, la política, deberá ocuparse de facilitar consensos. Debido al eterno conflicto político suscitado a raíz de la hiperinflación de los derechos, la política deberá propiciar ámbitos en los 
que la mayoría se ponga de acuerdo. Y esto que la mayoría quiere que sea, va a ser independientemente de su verdad (carácter consensual).

En esta versión racionalista aggiornada, en lugar de sacar al ciudadano del escepticismo, la política lo confirma. En efecto, ella le enseña al ciudadano que su basamento es el poder, no la verdad y lo justo. La política proclama, urbi et orbi, que ella no quiere saber nada con Sócrates ni con Platón: su ídolo es Trasímaco.

Pero hay más. No solo proclama su opción a favor de Trasímaco, sino que, además, fomenta la privatización de la política. Y en esta privatización, la lógica política de sus actores principales no responde al bien común, sino a la de los propios intereses. Las demandas justas de la "gente", si bien están presentes solo como machacona retórica, tienen un escasísimo margen en la agenda de los políticos.

Frente a la desnaturalización de estas dos importantes dimensiones de la existencia humana, la religión y la política, el hombre contemporáneo, escéptico, ha terminado refugiándose en su propio yo. Y este yo ha pasado a ser el Único, usando la denominación de Max Stirner.

La unidad de este Único radica en su mera vida biológica. Nada hay situado más allá del propio vivir y de sus exigencias que, en la actualidad, se denominan "derechos". Proclama Stirner:

¡Fuera entonces toda causa que no sea entera y exclusivamente la mía! Mi causa, me dirán, debería ser, al menos, la "buena causa". ¿Qué es lo bueno, qué es lo malo? Yo mismo soy mi causa, y no soy ni bueno ni malo; ésas no son, para mí, más que palabras. Lo divino mira a Dios, lo humano mira al hombre. Mi causa ni es divina ni humana, no es ni lo verdadero, ni lo bueno, ni lo justo, ni lo libre, es lo mío, no es general, sino única, como yo soy Único. Nada está por encima de mí (Stirner, 2007: 15).

El narcisismo del Único conduce al hombre a considerar a la legislación como una extensión de su propio yo. De allí que la razón de ser de la misma radique en satisfacer los deseos de su vida biológica, incluyendo, si ello fuese necesario, la muerte de inocentes. De esta tarea, en una primera etapa, se ocupan las "minorías intensas" valiéndose de la retórica de "ocuparse de la gente". 
$\mathrm{Al}$ respecto, Wilhelm Reich consideraría que la verdadera revolución ya se ha cumplido en Occidente. El individuo solo debe satisfacer sus impulsos vitales. La cuestión de la trascendencia ya no importa a nadie. La propuesta de Reich parece haber funcionado: crear una "[...] ideología favorable a la sexualidad" y ponerla "[...] después en práctica por medio de una legislación y un nuevo orden de la vida sexual” (Reich, 1993: 23).

Para Del Noce, una sociedad que no conozca otro principio que la pura expansión de la vitalidad se ordena inexorablemente a su disolución. De allí que afirme que el totalitarismo actual es diverso de las otras formas de totalitarismos: este promueve y defiende el proceso de disolución (Del Noce, 1993: 168).

Stirner otorga razón a Del Noce cuando afirma:

Yo soy el propietario de mi poder, y lo soy cuando me sé Único. En el Único, el poseedor vuelve a la nada creadora de la que ha salido. Todo ser superior a Mí, sea Dios o sea el Hombre, se debilita ante el sentimiento de mi unicidad, y palidece al sol de esa conciencia. Si yo baso mi causa en Mí, el Único, mi causa reposa sobre su creador efímero y perecedero que se consume a sí mismo, y Yo puedo decir: Yo he basado mi causa en Nada (Stirner, 2007: 371).

Del Noce tiene una profunda convicción: resulta insuficiente la política para salvar a Occidente. La profunda decadencia cultural que lo aqueja, ya lo hemos expresado, tiene su causa en la pérdida de la dimensión metafísica y moral.

Es menester que se produzca un "despertar religioso" (Del Noce, 1993: 169) para hacer que la religión, la patria y la familia sean consideradas como ideales supremos y no como instrumentos prácticos. Es necesario recuperar el sentido de aquello que no sirve y que se llama verdad. Y no sirve, precisamente, porque la verdad es un fin en sí misma. Maritain:

Expresaba, al respecto, el destacado filósofo francés Jacques

La metafísica exige una cierta purificación de la inteligencia; supone también una cierta purificación del querer y que se tenga el valor de adherirse a lo que no sirve, a la Verdad inútil. Nada es sin embargo más necesario al hombre que esta inutilidad. Hemos menester, no de verdades que nos sirvan, sino de una verdad a la 
cual sirvamos. Pues ella es el alimento del espíritu; y la base de nuestra grandeza es el espíritu (Maritain, 1978: 24).

Si la Iglesia Católica recuperase el cultivo de un intellectus fidei a partir de una filosofía del ser, estaría en condiciones de ocuparse de aquello que no se deja "agarrar con las manos". Pero para esto es necesaria una paideia integral que recupere la verdadera dimensión política y religiosa del hombre.

$\mathrm{Al}$ mencionar el intellectus fidei nos estamos refiriendo a la tarea de formación de la vida interior del cristiano. No olvidemos que la metafísica cristiana afirma que, por voluntad divina, el ser es uno-múltiple y, por eso, ha insistido en la importancia de la individualidad. De allí el peligro de olvidar esta verdad fundamental apelando a universales como pueblo, comunidad, gente, etc.

Del Noce insiste en el valor de la persona, de aquel individuo que representa una realidad distinta dentro de la naturaleza común compartida por todos los hombres. Para el filósofo italiano resulta imprescindible reivindicar en el hombre ese principio espiritual que es independiente de la sociedad, del pueblo.

Este hombre ya no será el hombre de una sociedad, sino que será persona. Así, como hombre individuo, constituirá el fin último de la ordenación social en la línea democrático-personalista afirmando, de este modo, la idea cristiana de hombre (Del Noce, 2001: 259).

Las palabras de Del Noce guardan absoluta actualidad. A partir de la recuperación de la verdadera naturaleza del catolicismo podrá recobrarse la auténtica naturaleza de la política. Esto supone, lo reiteramos, pensar la política desde una dimensión metafísica que permita dar pleno sentido a sus acciones.

Consideramos que el Único no está para nada satisfecho con la condición en la que se encuentra. Su radical escepticismo y solipsismo lo mantienen sumido en un nihilismo radical, en una total falta de sentido. La nada, como nos dice Stirner, es su único sustento.

Sin embargo, su aislamiento subjetivo no resulta suficiente para ahogar esa profunda sed de sentido y de eternidad que brota de su espíritu. Este deseo espiritual demanda que la religión recupere su verdadera 
naturaleza. Solo esta dimensión puede invitarlo, nuevamente, a abrazar la verdadera salvación que otorga el Dios hecho hombre.

\section{Referencias Bibliográficas}

Castellano, D. (2011). "Augusto Del Noce e la questione del racionalismo politico. Appunti per una relazione”. En Augusto Del Noce (19101989). Filosofia politica, crisi morale e storia contemporanea. Atti del Convegno nel ventennale della norte di Augusto Del Noce, organizzato dal Consiglio Nazionale delle Ricerche e dall'Università di Cassino in collaborazione con la Fondazione Centro Studi "Augusto Del Noce" di Savigliano (Roma 20 novembre - Cassino 21 novembre 2009). Roma: Pagine.

Cornoldi, G. M. (1872). Lezioni di filosofia ordinate allo studio di altre scienze. Firenze: Luigi Manelli.

Del Noce, A. (1972). I caratteri generali del pensiero político contemporáneo. Lezioni sul marxismo. Milano: Giuffrè.

Del Noce, A. (1980). Tesis sobre Feuerbach en Karl Marx. Escritos juveniles ( $2^{\mathrm{a}}$ edición). Madrid: Crítica Filosófica.

Del Noce, A. (1982). "L'idea di modernità". En Modernità. Storia e valore di un'idea. Contributi al XXXVI Convegno del Centro di Studi filosofici di Gallarate 23-24-25 aprile 1981. Brescia: Morcelliana, pp. 26-27.

Del Noce, A. (1983). "Le radici filosófico-politiche dell'ateismo contemporaneo". Il Nuovo Areopago, 2(6), 7-28.

Del Noce, A. (1990a). Giovanni Gentile. Per una interpretazione della storia contemporanea. Bologna: Il Mulino.

Del Noce, A. (1990b). Il problema dell'ateismo (4 ${ }^{\text {a }}$ edizione). Bologna: Il Mulino.

Del Noce, A. (1992) Filosofi dell'esistenza e della libertà. Spir, Chestov, Lequier, Renouvier, Benda, Weil, Vidari, Faggi, Martinetti, Rensi, Juvalta, Mazzantini, Castelli, Capograssi. Milano: Giuffrè editore.

Del Noce, A. (1993). "Alle radici della crisi". En Rivoluzione, Risorgimento, Tradizione. Scritti su "L'Europa" (e altri, anche inediti). Milano: Giuffrè Editore.

Del Noce, A. (1994). I cattolici e il progresismo. Milano: Leonardo.

Del Noce, A. (2001). Scritti politici. 1930-1950. Soveria Manneli: Rubbettino.

Del Noce, A. (2007a). Modernità. Interpretazione transpolitica della storia contemporanea. Brescia: Morcelliana.

Del Noce, A. (2007b). Secolarizzazione, nichilismo e cristianesimo. En Verità e ragione nella storia. Antologia di scritti. A cura di Alberto Mina. Milano: Biblioteca Universale Rizzoli.

Del Noce, A. (2012). Teología de la Secularización y Filosofía (Traducción y Estudio Introductorio a cargo de Carlos Daniel Lasa). Puebla, México: UPAEP. 
Del Noce, A. (2015). L'epoca della secolarizzazione. Torino: Nino Argano Editore.

Del Noce, A. (2016). Rousseau. Il male, la religione, la politica. Con le ultime lezioni su Rosmini. Brescia: Editrice La Scuola.

Dezza, P. (1940). Alle origini del neotomismo. Milano: Fratelli Bocca Editori.

Engels, F. (1955). Ludwig Feuerbach y el fin de la filosofía clásica alemana. En Marx, C., \& Engeles, F. Obras escogidas en dos tomos (Tomo II). Moscú: Ediciones en Lenguas extranjeras.

Gadamer, H. G. (1993). El problema de la conciencia histórica. Madrid: Tecnos.

Gentile, G. (1962). Il modernismo e i rapporti fra religione e filosofía ( $3^{\mathrm{a}}$ edizione). Firenze: Sansoni.

Gioberti, V. (1856). Della riforma cattolica della Chiesa. Frammenti en Opere inedite di Vincenzo Gioberti (Volume I). Torino: Editori Eredi Botta. Paris: M. Chamerot Libraire.

Lasa, C. D. (2017). “Teología del pueblo: ¿teología o ideología?”. Anales de Teología, Vol. 19.2, 221-249.

Laporte, J. (1950). Le Rationalisme de Descartes (Nouvelle édition revue et autmentée). París: P.U.F.

Malusa, L. (1982). "Riflessioni sulla restaurazione tomista in Italia". En Modernità. Storia e valore di un'idea. Contributi al XXXVI Convegno del Centro di Studi filosofici di Gallarate 23-24-25 aprile 1981. Brescia: Morcelliana.

Maritain, J. (1971). Filosofía de la Historia ( $5^{\text {a }}$ edición). Bs. As.: Troquel.

Maritain, J. (1978). Distinguir para unir o los grados del saber. Bs. As.: Club de Lectores.

Reich, W. (1993). La Revolución sexual. Para una estructura de carácter autónoma del hombre. Barcelona: Planeta-Agostini.

Ritter, J. (1970) Hegel et la Révolution française. París: Beauchesne.

Rosmini, A. (1997). "Filosofia della Politica". En Opere Politiche. Roma: Città Nuova.

Saitta, G. (1912). Le origini del neotomismo nel secolo XIX. Bari: Laterza. Stirner, M. (2007). El Único y su Propiedad. Bs. As.: Editorial Reconstruir.

\footnotetext{
${ }^{1}$ Sistema que cree posible realizar la perfección dentro del orden de las cosas humanas. Por eso, es capaz de sacrificar el bien presente en aras de la imaginada perfección futura.

2 Pueden consultarse, al respecto: Saitta, G. (1912). Le origini del neotomismo nel secolo XIX. Bari: Laterza. También: Dezza, P. (1940). Alle origini del neotomismo. Milano: Fratelli Bocca Editori.

3 Palabras que cita Del Noce, haciendo referencia a lo afirmado por G. A. Borgese en su escrito La vita e il libro. Cfr. Del Noce, A. (1990). Giovanni Gentile. Per una interpretazione della storia contemporanea. Bologna: Il Mulino, 199.

4 "Contraddizione tra il secolo e il modo in cui s'intende il Cristianesimo. Quello è progressivo, questo vien tuttavia esposto in quella forma che aveva nelle età regressive. Da ciò nasce la sua decadenza. Necessità di una riforma che metta il Cristianesimo d'accordo col secolo. Perciò senza spogliarlo della sua finalità celeste, bisogna svolgerne l'elemento terreno e farne una civiltà. Tal riforma deve abbracciare l'esplicazione del dogma, l'indirizzo del culto, il genio della gerarchia. Roma è ancor oggi ciò clic era nel medioevo. Quindi sua declinazione.”
} 


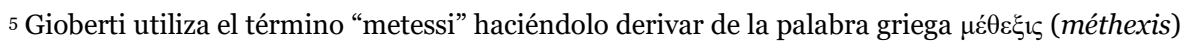
que significa, en términos generales, participación, comunicación. Para Gioberti, entre Dios y el hombre existe un movimiento circular unitivo. Dios, en cuanto creador del existente, de creaturas semejantes a Él, realiza, en una fase descendente, el momento de la imitación. Cuando, contrariamente, el mundo y los hombres en un movimiento ascendente retornan a Dios, se realiza el momento de la méthexis por el cual el existente vuelve a Dios.

6 "Le ristorazioni sono ascensive o discensive. Le prime ritornano all'antico avanzando verso il nuovo; e durano. Le seconde ritornano al vecchio e si oppongono al nuovo; non allignano. Le une conformi, le altre contrarie alla legge del progresso cosmico. Le prime sono dialettiche, le seconde sofistiche. Le une metessiche e le altre mimetiche. [...] Il cattolicismo si può ristorare nei due modi. La ristorazione del secondo genere che oggi si fa è vana; inoltre è perniciosa; fa l'effetto contrario [...] la ristorazione del secondo genere è retrograda, non è organica, non è creativa. Ogni ristorazione che vuol durare dee essere un'evoluzione, una trasformazione, e quindi una creazione. Dico trasformazione non disformazione."

7 Cuando hacemos referencia a razón crítica pensamos en aquella actividad de la conciencia que se funda en el rechazo de todo lo que le venga desde fuera: de lo transmitido (la tradición), de lo dado por la physis y leído por la inteligencia (metafísica), de lo revelado. Por eso decimos que la revolución, la idea de ruptura, es sucedánea a la idea de razón crítica.

8 Gilson, en su importante estudio sobre San Agustín, refiere que el santo de Hipona tenía necesidad de contar ya desde la vida presente, para llegar a conocer y amar a Dios, con una certeza incondicionada, prueba de nuestra aptitud para la Verdad total y beatificante (Gilson, É. (1943). Introduction a l'etude de Saint Augustin. París: J. Vrin, p. 9). 